\title{
Sex Segregation and the Participation of Transgender Adults in Recreational Sport in British Columbia, Canada
}

Tung Nguyen, Vancouver Island University, Canada

\section{Chapter Summary}

The lack of a formal policy on transgender participation in recreational sport results in transgender people struggling alone with stigmatization. Recreational sport guidelines identify inclusion as an imperative in recreational sport participation, yet they have failed to lay out the means to achieve it. Considering this issue and opportunity, the purpose of this case study is to determine how transgender adults' participation in recreational sport in British Columbia (BC), Canada is informed by their experiences with sex-based segregation structures in recreational sport and, secondly, to inform an enhanced and intentional change in transgender-inclusive policies and practices in terms of sex-based segregation structures in recreational sport in BC, Canada. With a qualitative research design, this case study approached the issue from two angles. First, five written biographies and film documentaries about transgender people in sport were used for a textual data analysis. Second, eleven individual semi-structured interviews were conducted with transgender adults recruited from recreational sport leagues and transgenderrelated organizations across BC. Findings show multi-level transgender stigma, a lack of explicitness about transgender inclusivity, and best practices recommended by transgender participants themselves in recreational sport. Implications and lessons learned from the case study include a need for widespread education on transgender topics, skill-based segregation over sex-based segregation, and strategies to build explicit transgender-inclusive sporting environments. Lastly, discussion questions, arising out of the study, are provided and serve as recommendations for future research.

\section{Learning Objectives}

After reading this chapter, learners will be able to:

1. Better understand how transgender adults' participation in recreational sport in BC, Canada is informed by their experiences with sex-based segregation structures in recreational sport;

2. Learn from best practices recommended by transgender participants in recreational sport in BC;

3. Concretize the idea of creating transgender-inclusive policies and practices in recreational sport in BC. 


\section{The Issue, Opportunity, or Trend}

In Canadian sport, there are several issues related to public policy (Thibault \& Harvey, 2013), one of which is the lack of a formal policy specifically focused on recreational sport participation (Donnelly, 2013). Tasked by the Government of Canada (2017) to set a direction for all governments, institutions and organizations in sport, the Canada Sport Policy 2012 (CSP 2012) - the overarching sport policy for the period of 2012-2022-emphasizes that recreational sport participants should "have the opportunity to participate ... for fun, health, social interaction and relaxation" (Sport Canada, 2012, p. 8). Furthermore, with inclusion as one of the new foundational elements, the CSP 2012 aspires to reach a broader participation (Frisby \& Ponic, 2013) by increasing the involvement of historically excluded populations. Nevertheless, both the CSP 2012 and its predecessor (CSP 2002) fail to lay out the means to achieve this outcome (Donnelly, 2013), even though they identify it as an imperative goal. Frisby and Ponic (2013) further argue that concrete policies with action plans are lacking for those underrepresented groups, including the community of two-spirited, lesbian, gay, bisexual, transgender, queer/questioning, and other identities (2SLGBTQ+).

Aligned with the CSP 2012, A Framework for Recreation in Canada: Pathways to Wellbeing highlights inclusion as one of the goals with priorities to "enact policies of non-discrimination on the basis of gender identity and gender expression [and] provide a welcoming and safe environment for people with all sexual orientations and sexual identities" (Canadian Parks and Recreation Association [CPRA], 2015, p. 23). These proclamations point to issues surrounding the inclusion of transgender individuals in sport. Canadian governments at local, regional, and provincial/ territorial levels are urged by the CPRA to implement action plans in their jurisdiction with the employment of this framework.

The purpose of this study is to determine how transgender adults' participation in recreational sport in BC is informed by their experiences with sex-based segregation structures in recreational sport, and inform an enhanced and intentional change in transgender-inclusive policies and practices in terms of sex-based segregation structures in recreational sport in BC. A textual data analysis and individual semi-structured interviews were performed with transgender recreational sport participants. Both textual data and data from interviews were analyzed using a thematic analysis approach. The study was conducted as part of the requirement for the author's Master of Arts in Sustainable Leisure Management program at Vancouver Island University (Nguyen, 2021). The present study took place in BC, Canada.

The Government of British Columbia, recognized as one of the leaders in Canada in sport participation in general (Government of British Columbia, n.d.), released "Pathways to Sport", which outlines a strategic framework for the sport sector in BC, addressing the years 2020 to 2025. This framework, similar to other frameworks and policies mentioned above, asserts the significance and urgency to make sport more inclusive, especially in relation to gender equity. The guidelines, albeit towards a noble goal, remain ambiguous, and lack a specific set of actions necessary to 
mitigate issues related to transgender inclusion in recreational sport. Interestingly, in the view of Pal (2010), both action and inaction chosen by governments are integral parts of policy. In other words, having no policy about the inclusion of transgender people in recreational sport could be considered one of governments' default policies. Indeed, perceived to be of little political gain, recreational sport participation has received limited involvement from the Canadian federal government and is regarded to be a matter of provincial jurisdiction (Donnelly, 2013). This limitation has led to non-profit organizations and local parks and recreation departments being the 'default' recreational sport providers and advocates (Donnelly, 2013).

\section{The Innovation}

\section{Case Context}

For the past decade, the Canadian Centre for Ethics in Sport ([CCES], n.d.) has been immensely proactive in providing guidance for Canadian sport organizations to create more transgender-inclusive sport policies. The CCES (2016) makes it clear that, especially for sport played at recreational levels, all individuals "should be able to participate in the gender with which they identify and not be subject to requirements for disclosure of personal information beyond those required of cisgender athletes. Nor should there be any requirement for hormonal therapy or surgery" (p. 26). In addition, the CCES (2016) suggests that individuals, self-identifying outside of the gender binary, be able to move “between men's/women's teams more than once, or simultaneously participating on a men's team in one sport and the women's team in another" (p. 25).

Given the lack of a formal policy on recreational sport participation, as described in the "The Issue, Opportunity, or Trend" section of this study, many recreational sport organizations in BC have adapted their policies to the CCES's recommendations (2016; 2018), including Field Hockey BC, Vancouver Ultimate League, and BC Wheelchair Sport Association. Such organizations rule that transgender people can participate in recreational sport in the gender they identify without having to make any changes to their body.

Yet, there are BC sport organizations that still subscribe to the gender binary and embrace transgender inclusion policies only where medical interventions are considered mandatory, such as Volleyball BC and the BC Amateur Softball Association. Restrictions of sex-based participation are applied in most recreational sport organizations in BC. Co-ed teams are offered in some leagues, such as Urban Rec, Victoria Sport, and Social Club; however, there are stringent requirements as to the number of men and women allowed on those co-ed teams, thus forcing participants to identify within the traditional gender binary. Therefore, the current context of recreational sport policies in BC, related to the participation of transgender people, can be summarized in two points: there is inconsistency in transgender inclusion policy implementation across recreational sport organizations in BC, and secondly, as Leong and Bartlett (2017) conclude, sport authorities are heavily "wedded to the idea of a sex binary" (p. 1817). Consequently, it 
is an on-going challenge for transgender people, who do not identify within the binary or who do not alter their body to fit the binary, to participate in sport.

\section{Stakeholders Involved}

A primary stakeholder in the issue surrounding the inclusivity of transgender people in recreational sport is the transgender community. While this community is directly affected by this issue, sport policy makers and recreation providers in $\mathrm{BC}$ constitute two other stakeholder groups who play a pivotal role in how transgender inclusivity in sport is addressed. Furthermore, the decision as to whether or not recreational sport environments are transgenderinclusive is also made by those involved in the sport, such as team members, coaches, or referees, thus making them important stakeholders. Additionally, individuals who are indirectly involved in recreational sport, including bystanders, 2SLGBTQ+ organizations, and the media, also have a stake in this issue. It is important to note that all stakeholders can be both part of the problem and the solution, and each stakeholder group has their own unique role to play towards creating greater inclusivity of transgender people in recreational sport.

\section{Approach Used and the Impact}

\section{The approach}

A qualitative approach was used in this study to facilitate understanding of sport policy making as it relates to how recreational sex-segregated sport is experienced by transgender participants with the goal to effect change in policies and practices. The methods chosen for this case study were textual data analysis and semi-structured interviews. Textual data analysis involves reviewing and evaluating documents including the examination and interpretation of the data (Bowen, 2009). A list of documents that the study drew from are provided in Table 1. Data from textual analysis showed a persistence of transgender exclusion both at structural and interpersonal levels. Also, the impacts that sex segregation has on gender dysphoria and the importance of having safe and welcoming environments for transgender people, were signified as part of textual data analysis findings. This analysis was performed to sensitize the researcher with the topic of transgender experiences in sport prior to conducting semi-structured interviews. Sensitizing concepts can be changed, supplemented, or replaced by concepts that emerge after the main data analysis is conducted (Padgett, 2004). In this study, sensitizing concepts (textual data analysis findings) complement emergent concepts (interview data findings). All three thematic areas from the textual data analysis findings could be allocated to support only two out of three thematic areas from the interview data findings. As a result, findings from the interview data were found to be broader than, but also strengthened by, findings from textual data analysis. Thus, findings from the interview data replaced findings from textual data analysis and succeeded to be the main findings of the study. 


\section{Table 1}

Documents for Textual Data Collection

\begin{tabular}{llll}
\hline No. & Document title & Document type & Author \\
\hline 1 & In The Turn & Documentary film & Tremblay, 2014 \\
& $\begin{array}{l}\text { Transgender Journey: The Struggle } \\
\text { for Rights and Respect }\end{array}$ & Documentary film & $\begin{array}{l}\text { Canada's Cable Public Affairs } \\
\text { Channel, 2016 }\end{array}$ \\
& $\begin{array}{l}\text { My name is Jay, I Transitioned and } \\
\text { I'm a Disabled Young Athlete }\end{array}$ & $\begin{array}{l}\text { Biography } \\
\text { (book chapter) }\end{array}$ & Anonymous, 2017 \\
& $\begin{array}{l}\text { Becoming me: Transitioning, Training } \\
\text { and Surgery }\end{array}$ & $\begin{array}{l}\text { Biography } \\
\text { (book chapter) }\end{array}$ & McCormack \& Hanold, 2017 \\
& Man Made & Documentary film & Cooper, 2018 \\
\hline
\end{tabular}

The other method chosen for the study was semi-structured interviews, consisting of "a blend of closed- and openended questions, often accompanied by follow-up why or how questions" (Adams, 2015, p. 493). Given the COVID-19 pandemic and public health directives in 2020 , in-person interviews were not possible. Instead, interviews were conducted individually with each participant using an online video-conferencing platform (i.e. Zoom). All interviews lasted 45 to 60 minutes in duration and adhered to the use of an interview protocol. The study participants were 19 years of age or older, able to speak English, had a gender identity or sex different from their gender or assigned sex at birth, and had engaged or were interested in recreational sport in BC. The sport engagement frequency level of the study's participants was not a criterion in participant recruitment since the study aimed to better understand the lived experience transgender people had with current recreational sport policies and practices, and if the interviewee was a new or regular sports user. Details about each participant are shown in Table 2. 


\section{Table 2}

Study Participant Profiles

\begin{tabular}{llll}
\hline No. & Name used in the study & Self-identifies as & Recreational sport(s) played \\
\hline 1 & Nicola & Transgender woman & Soccer \\
2 & Terra & Transgender woman & Soccer \\
3 & Darrien & Transgender woman & Ice hockey \\
4 & M. & Transgender woman & Soccer \\
5 & L.C. & Transgender woman & Hockey \\
6 & Tiffany & Transgender woman & Basketball \\
7 & Emily & Transgender woman & Soccer \\
8 & Marisa & Transgender woman & Ice hockey \\
9 & Kira & Transgender woman & Volleyball \\
10 & Remy & Transgender man & None (looking to play) \\
11 & J.T. & Transgender man & Soccer, volleyball \\
\hline
\end{tabular}

\section{The Impact}

Three main themes emerged from the data analysis and represent three key findings: (1) stigma, (2) lack of explicitness about transgender inclusivity, and (3) heaven for sports.

\section{Finding 1: stigma}

A multi-level approach was used to examine stigma at structural and individual levels. Four types of stigma were identified: structural stigma, enacted stigma, felt stigma, and internalized stigma (Herek, 2007; 2009). All stigma types, except internalized stigma, were found in the study's first finding, with each type feeding and building on each other. Structural stigma was manifested through the implementation of recreational sport policies, rules, registration forms, and team formation, all of which are designed based on the gender binary in the best interests of cisgender people. As an example, "[in co-ed teams], you have to [have] a minimum of three women on the team out of six 
players at any given time, or else it will be disqualified, and the game would be called off" (Kira, transgender woman). Similarly, on the registration form:

You have to ... click a little box that says ... "I am a woman" to play in that [women's] league. ... I'm sure non-binary people just ... tick that box and they're like, "Well, fuck you. That sucks. I guess I'll just do that because I have to." It seems like an easy first step to let non-binary people fit into a league that's consistent with their hormone profile, without asking them to misgender themselves. (Emily, transgender woman)

Subsequently, this kind of stigma naturalizes the gender binary while still being informed by it, leading to individually enacted stigma in recreational sport against transgender people. Participants recalled discriminatory remarks, such as "I don't want that transgender playing in any of these, on any of the teams. I don't want them in soccer, or anything" (M., transgender woman), or "Is she even a she?! .... Oh, she probably has a penis anyways!" (J.T., transgender man). Enacted stigma is conveyed through verbal but also non-verbal means of communication, namely microaggressions, such as when "people [do] not mak[e]ing eye contact in the handshake line" (Emily, transgender woman), and "never engage in conversation with you, always sit[ting] as far away as they can from you; it makes you feel they are telling you something without actually saying it" (L.C., transgender woman). Participant Emily shared in detail:

It's pretty subtle ... [in] a women's league and for everyone else ... the opposing team's coach would be saying "Mark her! [or] ... "Watch her!". They'd be using "she, her" pronouns for everyone else on the field, except me [they'd be saying "Mark them!"]. So, yes, it's not so much that I object to "they, them" pronouns or, like, offended by those, but it does reinforce that sense of being singled out and being visibly different. (Emily, transgender woman)

As a result, transgender participants who play recreational sport have to take steps to protect themselves for fear that they will be subject to this kind of stigma when they participate in sport, which refers to felt stigma:

We have less bad experiences because ... we don't put ourselves into places that allow us to have bad experiences. So maybe I would have attempted to join sports more. But I didn't even question it because subconsciously, I was like "Oh, there's no point, because it might be a problem". (Terra, transgender woman) As an example, transgender woman Nicola shared that "the worry about whether I would be accepted or not was the reason why I took a break and didn't play women's soccer right away after transitioning". Likewise, Kira (transgender woman) felt like she would "create unnecessary conflict" in the volleyball coaching environment if she revealed herself as a transgender woman. Although Kira did not see the need to disclose her transgender status, the problem is that she would be cornered with no choice but to keep it a secret if she ever wanted to make it known. She said:

When I'm coaching children, who's in charge of the children? The parents, right? I cannot come out to the children that I'm transgender, because then they're gonna go tell the parents. [If] the parents have [a] 
religious background or whatever, then they'll start pulling [their] children out of the class. And then I'm going to not have a job because there's no more children. (Kira, transgender woman)

This, in turn, ultimately supports the gender binary and reinforces the idea that the domain of sport is not compatible with the presence of transgender people, reinforcing transgender-excluded structures. The impact of stigma on transgender participants' engagement with recreational sport was well illustrated in this finding through a multi-level examination of stigma. Examples from the findings include disengagement in sport (Emily, Nicola), concealment of transgender status (Kira), and avoidance of sport-gendered facilities (Terra).

\section{Finding 2: Lack of explicitness about transgender inclusivity}

The second finding of the study describes a lack of explicitness about transgender inclusivity across recreational sport organizations. Transgender participants either reported feelings of uncertainty as to whether or not they would be welcome, or were under the impression that they would not be welcome to play recreational sports:

I just got this ... not really LGBT friendly vibe . . . because they don't say anything about being LGBT friendly. What would happen if there were, like, people who were not LGBT friendly? And [I wonder] if there would be anyone else like me there or if I would be, like, the only gay dude? . . Y Yeah, I worry about . . organizations like that. (Remy, transgender man)

A transgender woman participant, Terra, agreed with this observation, stating that "having a little Pride flag next to the logo always helps because it's like, okay, at least someone that set up the poster understands a little bit about the LGBTQ community". In another instance, according to transgender woman participant, Nicola, "[t]he women's league is fully accepting of trans people [but before joining], I just didn't know how to get into it, and I felt uncomfortable [so] I started off with a queer league and then people in that league introduced me to the women's league". Further corroboration included, "I think if I didn't have those connections, I would have an issue trying to find a team".

Similarly, Emily noticed the incapacity among her teammates to demonstrate their explicit transgender inclusivity; “for a lot of people, it's like, 'Oh, we support trans people', but maybe they're not great at explicitly being, like, 'Okay what do you need for support?' or like, 'What does that mean to you?'”. Emily further explained:

I think acknowledging that I'm trans allows you to be supportive in so many other ways. When there's a sign on a washroom that's like "Trans People Welcome", there's this sort of like authority saying like, "Yeah, it's fine. You'll be fine". I think that sort of like explicit acknowledgement is something that actually feels good to me ... You know it could just be things like when leagues ... have a, like "Oh it's Pride, so we're gonna like explicitly acknowledge like queer people who play in our league". And I really think that they should be trying harder to do that for trans people and being like "Yeah it's a thing. It happens". (Emily, transgender woman) 
Emily observed another indicator of a lack of explicitness about transgender inclusivity in a league: It'd be nice if they had a bit more like representation of queer and trans people in staff positions". She added, "I always felt quite good playing against this other team that had a couple of trans women on their team because ... if you're okay being the teammate of a trans woman, then like you should be okay playing against a trans woman. But it was usually not the case" (Emily, transgender woman).

The lack of explicitness about transgender inclusivity in policies and practices affects transgender recreational sport participation. Emily said, "I stopped playing [as] I don't want to really play in a league where I'm not sure whether people want me there" (Emily, transgender woman). Additionally, an avoidance of social sport environments was observed; as Remy added, "I also just ... kind of switched to solo sports [so] I don't have to worry about things like queer leagues and whether there's going to be an LGBT friendly space" (Remy, transgender man).

\section{Finding 3: Heaven for sports}

The third study finding emerged out of best practices recommended by transgender recreational sport participants to build a so-called 'heaven for sports'. The finding was organized in three main categories: education matters, skillbased segregation instead of sex-based segregation, and safe and welcoming sporting environments.

Participants recommended a far-reaching provision of education on transgender-related issues to all people involved in recreational sports, since "many people don't understand what trans is and are afraid to ask questions" (L.C., transgender woman) because of "fears of the unknown" (Kira, transgender woman). One suggestion put forward by L.C. was "they could do a little gender diversity training ... when they meet with the team representatives [because] every year they have, like, a league manager meeting". Alternatively, Kira, concerned with recreational sport organizations' approach to education of transgender-related issues, expressed:

They sort of teach the coach how to deal with it, but they don't teach the parent part. They don't teach the player part. They leave all the other components that are part of the game, you know? So, it's pretty solooriented, meaning they only focus on one area.... We need a more comprehensive approach for dealing with issues.... I guess the ideas would be nice if we can educate everyone involved [in recreational sport]. This is my heaven-heaven for sports. (Kira, transgender woman)

Most participants expressed a desire for recreational sport to not be segregated based on sex and gender but to be categorized by skill levels instead. This recommendation resonates with what Kane (1995) calls "the sport continuum", "in which many women routinely outperform men and, in some cases, women outperform most - if not all - men in a variety of sports and physical skills/activities" (p. 193). For transgender participants, recreational sport that is organized based solely on athletic skills means "treat[ing] them [us] as human beings, not because they're [we're] trans, not because they're [we're] gay, not because they're [we're] lesbian or whatever" (Kira, transgender woman). In addition, organizing recreational sport by skill level has the capacity to include non-binary folks who have 
been structurally marginalized due to the aggressive reinforcement of the gender binary in sport. On a side note, skillbased segregation over sex-based segregation will allow various options for players at all levels, given that participants in this study have different athletic abilities, ranging from a great amount of sport experience to limited sport experience; for instance, Marisa (transgender woman) preferred playing in a co-ed league to playing in a women's league because “it was fast; it was hard. It was lots of training, lots of coaching. That's the caliber that I'm used to and that's the caliber that I enjoy [and] I feel challenged by". By contrast, there were other participants who wished for "a team that wasn't so focused on ... the competitiveness of the sport". Tiffany claimed, "I love basketball. I don't really care if I win or lose. I do enjoy playing the sport but . . I I want there to be all options, at least for just going and having fun [be]cause it feels like there's a lot of hoops you got to jump through for one (Tiffany, transgender woman). Similarly, Remy added, "It would be nice to have more casual recreational opportunities ... I think that there's room for more, maybe like, drop-in or like less intense sports teams of various sports for LGBT people" (Remy, transgender man).

Moreover, participants emphasized the importance of safe and welcoming sport environments because "there's always the question of, okay, if I'm attacked, who am I going to talk to?" (Terra, transgender woman). Likewise, Kira mentioned that “it's recreational [sport], it's not competition. There's no guidelines for trans people [as] to where to take these things to". Safe and welcoming sports environments, from the participants' point of view, refer to sport environments free of stigma, where transgender-inclusive policies are in place, and participants are supported by teammates and coaches, particularly in instances of discrimination. Darrien (transgender woman) claimed, in her experience coaching in the men's league, she never heard any discriminatory comments aimed towards her but recalled "a colleague of mine [hers] did once ... and she kicked him off the ice and he was suspended for 10 games". Transgender man J.T. was reassured by the coaches that behaviours communicating discrimination and harassment should never go undisciplined. Yet, "you can make a policy saying, you know, this league is inclusive to different genders and all that but it comes down to the actual people... that make up the teams" (L.C., transgender woman). Participants described trans-only or queer-only sport spaces as places where they had a chance to "come together and celebrate our similarities and differences" (Darrien, transgender woman), and most importantly, experience "a sense of . . . community" (Emily, transgender woman). Nonetheless, non-queer, sport environments were also regarded as safe and welcoming spaces. M. (transgender woman) "contemplated quitting" recreational hockey many times due to instances of discrimination by participants; "I always had . . f four or five people on my team or friends that were really, 'No, keep on playing! Screw them!'”. Similarly, Terra's team captain even assured her that "when you're out, awesome; we will fight with you to say that you are a woman and, like, we'll come to that hill when we have to". Participants recognized that with them being treated as "just another teammate" (Darrien, transgender woman), or "just another person, another friend, another player" (Terra, transgender woman), being transgender was no longer an issue. 


\section{Implications \& Lessons Learned}

Implications and lessons learned are mostly found in the study's third finding, termed heaven for sports, meaning those best practices that were recommended by transgender participants themselves based on their own experiences. The first implication is the need to have a widespread provision of education on transgender-related topics. Although incorporating training and knowledge-sharing sessions for coaches, officials, staff, and participants is imperative, it needs to be implemented in such a way as to not further marginalize the transgender community or hurt other identities, such as persons of colour or sexual minorities. To achieve this, the training language must not reflect the gender binary, training information must be accurate, and training facilitators should be members of the transgender community. While many individuals, especially those who have the privilege of already being included in the sport system, may not find themselves interested in these training and knowledge-sharing sessions, recreation providers must understand that it is not a matter of interest but a matter of human rights (Voyles, 2019). That said, recreation providers should come up with more creative and interactive knowledge-sharing or awareness-building sessions to attract more attendees, optimizing the educational impact. As an example, it can be an exercise as simple as asking everyone to write their personal pronoun on a piece of paper, then swap it with the person next to them, and express how they feel having a new personal pronoun that might or might not correspond to their gender identity.

A recommendation is to organize recreational sports based on athletic skills instead of sex. Regardless of the gender people identify with, what category their biological characteristics fall into, or what people's abilities are, there will always be a place for people to engage in recreational sport based on their athletic skill level. This change could be implemented into eligibility policy, registration forms, team formation, team names, and uniforms. Given that this is a system change, recreation providers could apply this structure on a trial basis, such as in a tournament of teams, before deciding to widely implement it. When social change happens through small and incremental changes in people's lives (Hartmann, 2003), people can realize what works and does not work in order to change the system with incremental alternatives as opposed to changing everything at once.

The third implication is to create safe and welcoming recreational sport environments. The idea of safe and welcoming can be corroborated with recreation providers offering accessible, approachable, and knowledgeable points of contact where transgender participants can take their complaints or issues. For instance, inviting a trans person to be one of the points of contact is a good place to start. Also, excursions or team building activities, of which transgender participants are a part, can serve as a means not only to reiterate that transgender participants are welcome, but also to explore transgender participants' opinions about what is and what is not working in the league/organization in an informal and intimate way. 
The implications and lessons learned were informed by recommendations made by the study's participants through their own positive experiences which is indicative of what has been working for them in terms of policy practice. In other words, "if you look at what doesn't work, then you can come up with . . . what does work" (CPRA, 2020, 31:02). Need for improvement was identified in relation to how explicit transgender-inclusive recreation organizations should be. Recreation providers can start with having transgender people representing their community in key positions that can influence policy change. Also, social media is an effective channel to publicly express the organizations' vision that embraces the participation of transgender people. Monitoring and celebrating a calendar with days of significance of all people, including transgender people (e.g. Transgender Day of Remembrance, Trans Day of Visibility, Trans Awareness Month, etc.), helps showcase organizations' efforts to make every recreational sport participant matter. Likewise, having staff and personnel wear name tags with their pronouns, or introducing everyone's pronouns to a new league member would certainly nurture a culture of pronouns, discouraging misgendering and endorsing a safe sport environment. In addition, regularly participating in Pride-related events can bring about a positive image to an organization, facilitating access for transgender people, especially those who are hesitant to join sport. Moreover, recreation providers should seek feedback from transgender participants about how the organization can be supportive instead of making assumptions. Good intentions are not always positive if not executed properly. Kerpen (2017) explains, "Just because you thought you were helping the situation doesn't mean you were. In fact, you ruined everything! ... With that in mind, I came up with the Platinum Rule: Do unto others as they would want done to them" (p. 95 - 96, emphasis original). Fundamentally, the rule encourages people to see things from others' perspectives, refraining from imposing their own worldview onto others, for everyone is different. Recreation providers can surely incorporate this perspective into their strategic planning when it comes to designing policies and practices geared towards greater inclusivity of transgender participants.

\section{Emerging Scholar/Practitioner Reflections}

As a researcher exploring the experience of a community that I do not self-identify with, I was fortunate enough to have transgender participants put their faith in me by sharing their personal stories. I acknowledge a power differential here between myself as the researcher and the research participants. The researcher's role entails an 'extractive nature'; that is, I 'extracted' information from the studied participants to serve my purpose of publishing a master's thesis in order to graduate. It fulfilled both my personal as well as academic interests in advancing my understanding of the transgender community. My knowledge about gender and sport has significantly broadened from this research. I learned that, to create transgender-inclusive recreational sport policies and practices, it is imperative that transgender people are consulted, for it is "nothing about us without us". Also, I am now aware of several notions that I had never thought of before. For example, I had never thought that the use of the "they/them" pronouns could convey exclusionary connotations to a transgender individual, or about the unhealthy effects of overlooking a person's transgender identity. 
Transgender people will continue to find the domain of recreational sport unfriendly if recreation providers are grounded in the gender binary when designing policies and guidelines. Instead of applying bandages here and there to cover policy imperfections, existing policies and guidelines need to be shifted at their core to break the 'cis-tem'. After all, it should not be up to transgender people to find safe and welcoming recreational sport environments, but it is indeed the responsibility of recreation providers to create safe and welcoming recreational sport environments for everyone.

\section{Discussion Questions}

The discussion around transgender people and sex segregation structures in sport generally has received much attention from scholars of different study fields. However, it is far from being settled. A few questions that arise out of this study include:

1. What are the experiences of other populations within the transgender community (non-binary folks, transgender people throughout different stages of transition, transgender people who do not transition, or transgender youth and seniors) in recreational sex-segregated sport, given the current policies and guidelines in place?

2. How effective are the practices (e.g. education provision, social media presentation, and skill-based segregation) recommended by this case study's participants in enhancing greater inclusivity of transgender people in recreational sport?

In addressing the issue of there being no formal policy on the inclusivity of transgender people in recreational sport, it is imperative to understand why. Therefore, the following questions are worth discussing:

3. What are the experiences of recreational sport policy makers and recreation providers in creating transgender-inclusive recreational sport policies and practices?

4. What challenges do recreational sport policy makers and recreation providers face? How do they know if their recreational sport policies and practices are transgender-inclusive?

5. What are the barriers and the facilitators for transgender people in approaching recreational sport organizations? 


\section{References}

Adams, W. C. (2015). Conducting semi-structured interviews. In K. E. Newcomer, H. P. Hatry, \& J. S. Wholey (Eds), Handbook of practical program evaluation (4th ed.) (pp. 492-505). Jossey-Bass.

Anonymous, J. (2017). Chapter 2: My name is Jay, I transitioned and I'm a disabled young athlete. In E. Anderson \& A. Travers (Eds.), Transgender Athletes in Competitive Sport (pp. 23-31). Taylor \& Francis Group.

Bowen, G. A. (2009). Document analysis as a qualitative research method. Qualitative Research Journal, 9(2), 27-40. https://doi.org/10.3316/qrj0902027

Bowen, G. A. (2019). Sensitizing concepts. In P. Atkinson, S. Delamont, A. Cernat, J.W. Sakshaug, \& R.A. Williams (Eds.), SAGE Research Methods Foundations. https://www.doi.org/10.4135/9781526421036788357

Cable Public Affairs Channel. (2016). Transgender journey: The struggle for rights and respect [Video]. CPAC. https://www.cpac.ca/en/programs/documentaries/episodes/49023124/

Canadian Centre for Ethics in Sport. (n.d.). About us. https://cces.ca/about-us

Canadian Centre for Ethics in Sport. (2016). Creating inclusive environments for trans participants in Canadian sport: Guidance for sport organizations. https://cces.ca/sites/default/files/content/docs/pdf/ccestransinclusionpolicyguidance-e.pdf

Canadian Centre for Ethics in Sport. (2018). Creating inclusive environments for trans participants in Canadian sport: Policy and practice template for sport organizations. https://cces.ca/sites/default/files/content/docs/pdf/creating inclusive environments for trans participants i $\underline{\mathrm{n} \text { canadian sport-practice and policy template-final-e.pdf }}$

Canadian Parks and Recreation Association/Interprovincial Sport and Recreation Council (2015). A framework for recreation in Canada: Pathways to wellbeing. Ottawa: Canadian Recreation and Parks Association (February). https://www.cpra.ca/s/Framework-For-Recreation-In-Canada 2016-w-citation.pdf

Canadian Parks and Recreation Association. (2020, October 20). Intersectionality \& socio-cultural barriers to engaging/retaining girls, women and non-binary people. [Video]. Youtube. https://www.youtube.com/watch?v=NBenC0jYOSM\&t=17s

Cooper, T. (2018). Man made [Film]. Journeyman Pictures.

Donnelly, P. (2013). Sport participation. In L. Thibault \& J. Harvey (Eds.), Sport policy in Canada (pp. 177-213). University of Ottawa Press. 
Frisby, W. \& Ponic, P. (2013). Sport and Social Inclusion. In L. Thibault \& J. Harvey (Eds.), Sport policy in Canada (pp. 380-403). University of Ottawa Press.

Government of British Columbia. (n.d.). Pathways to Sport. https://www2.gov.bc.ca/assets/gov/sports-recreationarts-and-culture/sports/bc_sport_framework.pdf

Government of Canada (2017). Canadian Sport Policy. https://www.canada.ca/en/canadian-heritage/services/sportcanada.html\#a2

Hartmann, D. (2003). Theorizing sport as social intervention: A view from the grassroots. Quest (National Association for Kinesiology in Higher Education), 55(2), 118-140. https://doi.org/10.1080/00336297.2003.10491795

Herek, G. M. (2007). Confronting sexual stigma and prejudice: Theory and practice. Journal of Social Issues, 63(4), 905-925. https://doi.org/10.1111/i.1540-4560.2007.00544.x

Herek, G. M. (2009). Sexual stigma and sexual prejudice in the United States: A conceptual framework. Nebraska Symposium on Motivation Contemporary Perspectives on Lesbian, Gay, and Bisexual Identities, 65-111. https://doi.org/10.1007/978-0-387-09556-1_4

Kane, M. J. (1995). Resistance/transformation of the oppositional binary: Exposing sport as a continuum. Journal of Sport and Social Issues, 19(2), 191-218. https://doi.org/10.1177/019372395019002006

Kerpen, D. (2017). The art of people: 11 simple people skills that will get you everything you want. Portfolio Penguin.

Leong, N., \& Bartlett, E. (2017). Sex segregation in sports as a public health issue. SSRN Electronic Journal. https://doi.org/10.2139/ssrn.3026150

McCormack, R. \& Hanold, M. (2017). Chapter 3: Becoming me: Transitioning, training and surgery. In E. Anderson \& A. Travers (Eds.), Transgender Athletes in Competitive Sport (pp. 32-39). Taylor \& Francis Group.

Nguyen, T. (2021). Sex segregation and the participation of transgender adults in recreational sport. [Unpublished master thesis]. Vancouver Island University.

Padgett, D. K. (2004). Coming of age: Theoretical thinking, social responsibility, and a global perspective in qualitative research. In D. K. Padgett (Ed.), The qualitative research experience (pp. 297-315). Wadsworth/Thomson Learning.

Pal, L.A. (2010). Beyond policy analysis: Public issue management in turbulent times (4th ed.). Nelson Education.

Sport Canada. (2012). Canadian sport policy 2012. Department of Canadian Heritage. http://sirc.ca/CSPRenewal/ documents/CSP2012_EN.pdf 
Thibault, L., \& Harvey, J. (2013). Sport policy in Canada. University of Ottawa Press.

Tremblay, E. (2014). In the turn [Film]. Under The Milky Way.

Voyles, C. (2019, June 28). Sex segregation in sport: A denial of rights and opportunities for health. Health and Human Rights Journal. https://www.hhrjournal.org/2019/06/sex-segregation-in-sport-a-denial-of-rights-andopportunities-for-health/ 


\section{Author}

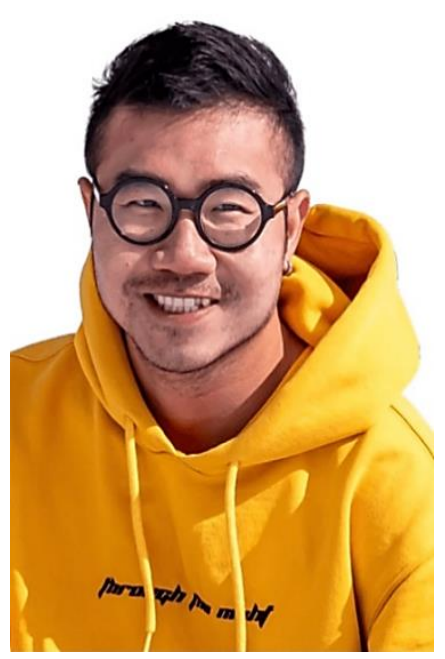

Tung Nguyen, MA. (he/him/his) is an graduate from the Master of Arts in Sustainable Leisure Management program (MASLM) at Vancouver Island University. He has been actively engaged in the $2 \mathrm{SLGBTQ}+$ community in $\mathrm{BC}$, having served as director for the Nanaimo Pride Society and currently sitting on the 2SLGBTQ+ Advisory Committee with the City of Vancouver. In addition, he has worked as the Diversity, Equity, and Human Rights (DEHR) Project Assistant for Vancouver Island University, developing a more suitable approach to DEHR issues for university staff, faculty members, and students. His research is primarily informed by his social justice and gender equity mindset, combined with his lived experience as a nonheterosexual person of colour. Tung is extremely grateful for the guidance and endless support from Dr. Suzanne de la Barre, Dr. Fenton Litwiller, and Dr. Judy Davidson throughout the study. All inquiries or comments can be sent to Tung at nguyen.sontung@outlook.com 